\title{
Utopías de la memoria: búsqueda de la trascendencia en la poesía de David Rosenmann-Taub
}

\section{The utopias of Memory: the search for transcendence in the poetry of David Rosenmann- Taub}

\author{
Naín Nómez \\ Facultad de Humanidades, Universidad de Santiago de Chile, Chile \\ nain.nomez@usach.cl
}

Resumen - El presente artículo se plantea desarrollar uno de los tópicos fundamentales de la obra del poeta chileno David Rosenmann-Taub, que consiste en buscar a través de su discurso poético una trascendencia que se arraiga en la memoria para exorcizar la presencia de la muerte. Dicha búsqueda, temática y discursiva, se instala a partir de un desplazamiento de los sujetos de los textos hacia un origen, que se visualiza como la nostalgia de un paraíso perdido y se despliega en el reencuentro con la familia, los amigos, los símbolos de la divinidad o el arraigo en la naturaleza. En esa tarea, el poeta utiliza estrategias discursivas que exorcizan el territorio de la muerte e intentan detener el viaje hacia el dolor, el vacío o la nada, por medio de un reconocimiento de lo vivido y lo trascendido o por medio de un imaginario que se vuelca hacia el "país de más allá», en donde convergen pasado y futuro.

Palabras clave: poesía chilena, memoria, utopía, trascendencia.

Abstract - The following article attempts to develop one of the main topics present in the work of Chilean poet David Rosenmann-Taub: the search for transcendence through his poetic discourse, rooted in the memory to exorcize the presence of death. This search, in its themes and discourses, is produced by the displacement of the text's subjects towards an origin, visualized as the nostalgia from a lost paradise that unfolds in the reencounter with family, friends, divine symbols and the roots of nature. In this task, the poet uses discursive strategies to exorcize the territory of death, attempting to prevent a journey towards pain, emptiness or nothing through the recognition of life and transcendence as well as through an imaginary upturn to a «country beyond», where past and future converge.

Keywords: Chilean Poetry, Memory, Utopia, Transcendence. 


\section{INTRODUCCIÓN}

Una línea central de desarrollo de la poesía de David Rosenmann-Taub es la búsqueda reiterada de una trascendencia que se arraiga en la memoria del sujeto (de los sujetos), para exorcizar la presencia de la muerte. Se trata tanto de una búsqueda temática como discursiva, que provoca un desplazamiento del sentimiento de agonía de los hablantes de los poemas, al mismo tiempo que celebra el despliegue de los sentimientos de los mismos (familia, amigos, Dios, naturaleza) y sus relaciones con el mundo. Como tópico fundamental en dicha poesía (como en gran parte de la poesía contemporánea latinoamericana), se visualiza la nostalgia por un paraíso perdido (inocencia, amor filial, jardín de la infancia, simbología de la música), cuyo soporte es un lenguaje esencial y primigenio, que se intenta reconstruir en forma insistente y obsesiva para sostener la precariedad de la vida. A través de esta tarea, el poeta utiliza estrategias discursivas que exorcizan el territorio de la muerte y «lentifican» el viaje hacia la agonía, el dolor, el vacío o la nada, por medio de la representación de un presente que se colma con lo vivido y lo trascendido o por medio del imaginario de un país más allá, en cuya utopía convergen el pasado y el futuro.

\section{CONTEXTOS, LIBROS, COMENTARIOS}

El primer libro de David Rosenmann-Taub, El adolescente, fue publicado en 1941 cuando el poeta tenía 17 años y pasó casi desapercibido para la recepción crítica, cuando Antonio de Undurraga, crítico y poeta, lo publica en la revista Caballo de Fuego de la Poesía. Con la primera edición de Cortejo y Epinicio, en 1949, las manifestaciones de admiración no se hicieron esperar: Premio del Sindicato de Escritores de Chile por el manuscrito y Premio Atenea de la Universidad de Concepción. El libro fue reeditado en 1978 y vuelto a editar en el año 2002, pero ahora transformado por el autor: la metaforización exacerbada, el ritmo clásico y la desgarradura emocional del primer texto dieron paso a una rigurosa síntesis de imágenes que desplazó la métrica y el carácter apostrófico de los versos hacia una tensión lingüística, fónica y significativa que el poeta hará suya en sus siguientes libros. Se trata de una obra que tendría cuatro volúmenes, de los cuales el segundo apareció con el título de El mensajero en 2003 a través de la editorial Lom, que ha iniciado la publicación de toda su obra desde el año 2002. El tercer volumen, titulado La opción, apareció durante este año (2011).

Después de la primera edición de Cortejo y Epinicio, en 1949, se publicaron los poemarios titulados Los Surcos Inundados (Premio de la Municipalidad de Santiago, 1951), La Enredadera del Júbilo en 1952, Cuaderno de Poesía en 1962, Los Despojos del Sol, Ananda Primera en 1976 y El cielo en la fuente en 1977, ambos en Buenos Aires. En 1978 se publica la segunda edición de Cortejo y Epinicio y Los Despojos del Sol, Ananda Segunda y en 1983 una serie de aforismos titulada Al Rey su Trono. Las ediciones chilenas de Lom han sido, además de las citadas, El Cielo en la Fuente/ La Mañana Eterna en el 2004, País Más Allá (2004), Poesiectomía (2005), Los Despojos del Sol (2006) y Auge (2007), que son parte de numerosos volúmenes donde se incluye también «En lugar 
de la sangre» (inédito). Los últimos textos publicados en Chile son Quince (Comentarios del propio poeta sobre sus textos, 2008) y La opción (2011). La prolífica producción de Rosenmann-Taub comprende además una serie de textos inéditos, entre los cuales están «El Regazo Luminoso", que recibió el Premio de Poesía de la Universidad de Concepción en 1951, "Ajorca de Europa", escrito entre los años 1976 a 1978, la revisión de los volúmenes segundo, tercero y cuarto de Cortejo y Epinicio y los doce volúmenes de Los Despojos del Sol. El poeta prepara asimismo una edición de El Cielo en la Fuente con comentarios propios. De manera general, hay que considerar que el poeta trabaja siempre simultáneamente en varios libros y proyectos. Por otro lado, se sabe que además del robo de un sinnúmero de manuscritos durante el Golpe Militar, el poeta perdió alrededor de cinco mil páginas en el saqueo de sus posesiones.

Si bien su primer libro no pasó totalmente desapercibido para la crítica chilena, posteriormente la ausencia del poeta del país (vivió en Buenos Aires, Venecia y Nueva York) y la publicación de algunos textos en editoriales pequeñas de Argentina lo silenciaron frente al público chileno durante un largo tiempo. A ello se agregan las dificultades de su lectura, que requiere un lector muy activo. Pero muchos críticos y escritores reconocieron su temprana obra, entre ellos María Carolina Geel, Malú Sierra, Víctor Castro, Carlos René Correa, Hernán Díaz Arrieta (Alone), Francis de Miomandre, Hernán del Solar, Vicente Aleixandre, Francisco Santana, Manuel Rojas, Armando Uribe y Alberto Rubio. Al reeditarse su obra en 1978 en Buenos Aires, otros críticos se suman a la valoración del poeta, lo que junto a su «redescubrimiento» actual lo ha puesto en consonancia con otras voces críticas, como María Nieves Alonso, Ignacio Rodríguez, Teodosio Fernández, Jaime Concha, Gwen Kilpatrick, Cristián Montes, Juanita Cifuentes, Paula Miranda, Álvaro Salvador, Erika Martínez, María Ángeles Pérez López, Sabrina Constanzo, Stefano Tedeschi e Ina Salazar. A partir de la labor de la Fundación Corda, una serie de estudiosos jóvenes han empezado a incursionar en su obra con nuevos desarrollos críticos y estéticos.

A título no sólo de inventario, sino también de mostrar la similitud de los registros críticos, a pesar de su diversidad temporal y estética, exponemos algunas de las opiniones y juicios sobre la producción del poeta.

A propósito de la primera edición de Cortejo y Epinicio, Hernán Díaz Arrieta (Alone) plantea en 1951 que: «[...] su Cortejo y Epinicio descuella, justamente, por la variedad de tonos, la abundancia de metros, ritmos y rimas — no desdeña éstas ni aquéllos- y la soltura con que maneja su delicado instrumental. Uno se siente a través de una selva, bien acompañado por invisibles voces, modernas, clásicas, arcaicas o revolucionarias, siempre en espesura y con profundidad de terreno» (3).

Poco después el crítico francés Francis de Miomandre, al referirse a Cortejo y Epinicio y Los Surcos Inundados, escribirá:

Estos dos libros poseen una calidad y un acento totalmente excepcionales. No veo a nadie, ni aun entre nosotros, que se atreva a abordar la expresión poética con tanta desgarradora violencia. El dolor de vivir, la desesperación y la amargura de las experiencias cotidianas, la vanidad de todos los impulsos de amor hacia la creación, la obsesión de la muerte inspiran, línea a línea, este lirismo desbordante de ardor y abatido peregrinaje. Para completar este retrato demasiado sumario, es preciso anotar la participación de un humor y una fantasía casi delirantes [...]. Poesía comprometida, sí, poesía comprometida, sin duda. Comprometida con la pena de vivir, comprometida con la solidaridad del dolor (6). 
Con respecto de Los Surcos Inundados, Carlos René Correa indicaba en El Diario Ilustrado que el autor "enfoca los temas con sabiduría exquisita; todo está en su lugar y hasta el juego de palabras y de imágenes era preciso allí donde Rosenmann-Taub lo colocó». Para agregar que «entre los poetas de la novísima generación en nuestras letras, el autor de este libro es, sin duda, de los más serios y originales. Tiene un dominio notable del idioma y de la técnica del verso» (2). Sobre el mismo poemario, su compañero de generación, Miguel Arteche, profundizaba en una reseña más enjundiosa:

Rosenmann-Taub no regresa a ninguna parte. Conoce su personal técnica, sabe la técnica del oficio y, lo más importante, con esas dos direcciones dominadas escribe una extraña, conmovedora poesía. Un análisis a fondo del libro descubriría el dominio de la adjetivación, la maestría en la técnica del verso: piénsese en la variación métrica de sus poemas, en la creación de palabras, en la riqueza de un vocabulario que le pertenece y que usa con familiaridad, sin que se vea detrás de él lo libresco.

En un encuentro de 1965 realizado en el sur de Chile, Armando Uribe introduce al poeta, expresando que su primer libro fue la mayor revelación de la década del 50 («Presentación», 88). El poeta Uribe insistirá en sus juicios de alabanza en una crónica más actual, para luego acusar que «todo lo de Rosenmann-Taub, con el tiempo ha pasado a ser ignorado. Apenas habemos algunos que afirmamos su máximo valor en Chile y fuera. Pero no lo escucha prácticamente nadie» («El Mayor Poeta», 2). Desde esa publicación (1966), la figura y producción poética de Rosenmann-Taub parece desaparecer del plano periodístico y crítico nacional, para reaparecer a fines de la década del setenta a raíz de las ediciones de Cortejo y Epinicio y Los Despojos del Sol en la editorial Esteoeste de Buenos Aires. Alberto Rubio, otro compañero de ruta del poeta, analiza perspicazmente algunos de los textos de Los Despojos del Sol, agregando que: «nos deja algo así como cósmicamente desolados, pero a la vez nos conforta con esa tranquilidad que sobreviene tras la presencia o la experiencia de un drama seguido del logro de una verdad» (3). El crítico Hernán del Solar se refiere a Cortejo y Epinicio, en la edición revisada, diciendo que: «es de una originalidad intensa, inalcanzable para la saeta trizadora de la lógica» y agregando: «una voz, la suya, sin que otra la iguale en nuestro orbe poético, canta internamente para que exista un eco en hombre o mujer de alma alzada hacia el sueño, al delirio, a la realidad viva que cruza por sus palabras» (3).

Con el inicio de las ediciones y reediciones de la producción poética de RosenmannTaub por Lom Ediciones en Chile desde el año 2002, se «redescubre» al poeta en el país a partir de sus presentaciones de libros y de algunas crónicas y reseñas en periódicos y revistas. La tercera edición de Cortejo y Epinicio apareció encabezada por una presentación de María Nieves Alonso, quien expresa y expone con emocionalidad apasionada:

El dolor, la desgracia, el desasosiego, la verdad, llaman desde las páginas de Cortejo y Epinicio, huérfanas, al parecer, de toda consolación, cruzadas por señales de finitud, deterioro y pérdida... aunque henchidas de ansiedad y deseo: nostalgia de absoluto, de pureza [...]. La dama calva, la cucaracha, la intemperie, los escombros, el estropajo, el polvo, la sombra, las zarpas, los cuchillos, las largas tijeras puntiagudas, los gusanos, los niños podridos, los borrachos macilentos, las espadas que rebanan los ávidos latidos, los sollozos, las arcadas, los asquerosos sueños, las goteantes calles sórdidas, los cajones vacíos, el llanto, los calcinados huesos, los fríos lechos, los escupos negros, el vacío absoluto y un león que charla y gime como el poeta, me esperan en esta poesía de la mortalidad, del desconsuelo, de la farsa y del horror del mundo (6-7). 
El montaje que expone Alonso dialoga con el montaje del propio poeta, para buscar nuevos caminos de exposición de su originalidad. Señala que la obra está llena de surtidores de lenguaje, que buscan los rastros de un paraíso perdido que se encuentra en la plegaria, en la desgracia, en la música, el dolor o la celebración.

Por su parte, Cristóbal Solari comenta la reedición de la siguiente manera:

\begin{abstract}
Sus poemas pueden leerse como una sonata de Beethoven o de Schubert. Sabemos que la interpretación musical deja un espectro de libertad al intérprete, pero está sujeta a reglas. Rosenmann-Taub también establece las propias. Los silencios en el corte de los versos tienen extensión, los que separan las estrofas, otra. Al interior del verso, la pausa de una «coma» es distinta a la de los «dos puntos» o a la del «guion»; la regularidad de los acentos, las reiteraciones paralelas, la métrica impecable (véanse sonetos como «Itrio» o «Schabat») forman una estructura rítmica en la que nada ha sido dejado al azar (2).
\end{abstract}

En su reseña, Solari señala las dificultades de la lectura del poeta, la importancia de la reedición y la singularidad de su lenguaje, así como la rigurosidad musical y el uso de figuras literarias que resaltan el ritmo por un lado y las tensiones que provocan las imágenes contradictorias.

No podemos terminar el recorrido por la crítica acerca de Cortejo y Epinicio sin referirnos al importante trabajo de Jaime Concha publicado en el año 2008 (al que nos referimos más adelante), que destaca la singularidad del poeta, su carácter vanguardista, los significados del título, las relaciones dialécticas entre la niñez y la muerte y otros tópicos que iluminan la producción primera del poeta. Al respecto, Concha señala:

[...] Cortejo y Epinicio nos propone en esencia el enlace misterioso - doloroso y gozoso a la vez- de la muerte y la niñez. No de la muerte por un lado y de la niñez por otro, porque eso sería simplemente una banalidad o un par de banalidades. Es el movimiento y la conjunción de ambas, el de la muerte en la niñez y la repristinación constante de lo muerto. Tal vez sea éste uno de los sentidos posibles de su enigmático título, su dialéctica más entrañable.

Por otra parte, y según se ha podido ver, Cortejo y Epinicio se vincula con una tradición de vanguardia endógena, que tiene egregios precedentes en la obra de Prado, de Mistral y de Cruchaga Santa María, por citar sólo los casos más claros y afines al poeta. En su aspecto más externo, ello se refleja bien en la actitud del autor frente a la versificación y a la cuestión métrica en general (16-17).

Por su parte, Ignacio Rodríguez escribe a propósito de la reedición de Los Despojos del Sol en el año 2006, que:

Sin concesiones, verbaliza lo imposible y nos transfiere al mismo tiempo a la eternidad y a la caducidad de toda la peripecia humana. Por lo demás, todo en él suena bellísimo, porque en el fondo es pura conciencia de crecimiento, la pura brevedad de lo absoluto. [...] Afirmo que no estamos frente a un libro: que estamos frente a nosotros mismos, desnudos como esos poemas, despojados de todo lo inesencial, exactos en nuestras carencias y en nuestra verdad (1-2).

En el breve repaso crítico presentado, rescatamos también una reseña de Pedro Gandolfo a propósito de la publicación de Auge (2007), en la que se reiteran las dificultades de la lectura de Rosenmann-Taub, especialmente en ese poemario: 
Auge es el séptimo título que el poeta chileno, radicado ya por largo tiempo en Estados Unidos, publica en los últimos años. Reúne 62 poemas con una unidad formal bastante clara. En general son poemas cortos, con una métrica breve, marcados por un ritmo en constante aceleración y ascenso o bien por abruptas detenciones estáticas. Para lograr estos efectos, Rosenmann-Taub recurre con frecuencia a los «dos puntos», que los emplea con gran maestría como verdaderos atajos semánticos, sonoros y gráficos: los versos se precipitan o son lanzados en una suerte de disparos en los cuales el poeta ahorra el máximo de recursos [...] El esfuerzo de Rosenmann-Taub por la negación de todo lo superfluo coloca los versos en el límite de la inteligibilidad. Se trata de querer liberar al lenguaje poético, desesperadamente, de su propia masa y de las leyes de gravedad, de modo que el tema se desmenuza y salpica cuando choca con las pausas, las rimas o las imágenes (1).

En una nota sobre el libro de los Quince autocomentarios del poeta, Paula Miranda indicaba que:

Una gran preocupación atraviesa, cruza, unifica estos quince poemas y sus comentarios: el problema del tiempo. El poema funciona como la memoria, solo ella permite otorgarle sentido a los acontecimientos, cargando las acciones y las situaciones de temporalidad, de un yo transcurriendo, dotando de sentido la existencia [...]. Pero el tiempo fundamental es un tiempo fuera del tiempo, es el tiempo del mito, el tiempo «en toda la extensión del tiempo», como en el verso «no había ni el vacío dese día postrero». Es el tiempo de los antepasados, el tiempo doloroso de Cristo [...]. De ahí la obsesión del hermeneuta por precisar siempre el lugar temporal en el que transcurre o se enuncia cada poema. De ahí sus inquietudes antitéticas: «¿El tiempo? Un instante que no dura. ¿El espacio? Un punto que está, sin estar, en ningún sitio» (269).

Durante el año 2010, Felipe Cussen publica un artículo donde se refiere paralelamente a la poesía de David y Mauricio Rosenmann-Taub y sus juegos metafísicos, mostrando que a pesar de tener tendencias divergentes, producen textos para conjurar la ausencia, que se afincan en un experimentalismo sonoro o gráfico y un tono humorístico o cercano a la ironía (173-191).

Cerramos este recorrido parcial de la crítica sobre el poeta, con una cita de la consistente presentación que encabeza la antología realizada por Álvaro Salvador y Erika Martínez en España del año 2010:

En la obra de Rosenmann-Taub, la poesía es una forma de conocimiento del yo y del mundo que otorga al poeta una condición de vidente. De ahí el carácter hermético de sus versos, formulado en los primeros libros en forma de cierto neorromanticismo y orientado, a lo largo de los años, hacia un fragmentarismo solipsista, sintético y más inmanente que trascendente. Su poesía parece partir de la asunción del fracaso del proyecto ilustrado, emprendiendo una apuesta irracionalista que se nutre de la vanguardia, la mística, el simbolismo pero también como dijimos, del romanticismo. En sus poemas, la razón poética alcanza donde no llegan las herramientas gnoseológicas de la razón positiva. No hay una negación de lo real, sino una ampliación de sus límites más allá de la percepción (14).

La recolección de opiniones anterior nos permite situar la crítica periodística en una marcación que comprende tres momentos de desarrollo: i) los inicios de las publicaciones en los años 50, que relevan la producción del poeta; ii) las reseñas esporádicas de algunos libros que se publican en Buenos Aires a fines de los setenta; y iii) el resurgimiento de la atención sobre el poeta a partir de sus publicaciones y reediciones en Chile desde el año 2002. Falta incorporar artículos publicados fuera de Chile y presentaciones de los últi- 
mos años, que por distintas razones no fueron agregadas en el recuento todavía parcial que aquí hacemos.

\section{EL ESPACIO DE LA MEMORIA EN CORTEJO Y EPINICIO: ESTRATEGIAS PARA "LENTIFICAR" LA MUERTE}

En el Encuentro de Joven Poesía Chilena, que se realizó en Valdivia en abril de 1965, se estableció una convivencia que reunió a parte importante de la «promoción» que ejerció gran influencia sobre los poetas posteriores, es decir Miguel Arteche, Efraín Barquero, Enrique Lihn, Jorge Teillier, Alberto Rubio, Armando Uribe Arce y David Rosenmann-Taub. Este último se inicia más cercano a la línea lárica de Teillier, Rubio y Barquero, pero como se aprecia al leer su poesía, si bien el tópico de la infancia y la nostalgia por el origen se relevan como elementos centrales en su obra, se separa de los poetas anteriores por la densa urdimbre de sus versos, tensos, ambiguos, rigurosos, contenidos en un discurso que nunca se consume a sí mismo. Rosenmann-Taub es un poeta donde los significantes, si bien no priman sobre los significados, resultan vitales para leer la significación.

Nuestro punto de partida es el libro Cortejo y Epinicio con sus tres ediciones (1949, 1978 y 2002). Se ha elucubrado sobre el título del poemario: ¿cortejo de la muerte e himno triunfal?, ¿uno después del otro, ambos a la vez, uno como inicio y el otro como fin? Es probable que todas esas respuestas resulten válidas, sobre todo si consideramos al menos dos elementos de carácter un tanto oblicuo. El primero se refiere a las portadas de las dos versiones, tema que con respecto a la primera ya abordó Jaime Concha ${ }^{1}$. Pensemos «Cortejo» como un nudo significativo que alude metonímicamente a la muerte y «Epinicio» como un canto de victoria que busca traspasar la finitud de la muerte. A nuestro juicio, resulta interesante comprobar que en la primera edición, tanto el lema vivit post funera virtus, como los utensilios de la escritura expuestos y las alas del ave — ¿fénix? - parecen señales que aluden a la relación que se da entre el libro (contenido y continente) y la articulación que se da entre la vida y la muerte como trascendencia o transformación. En la segunda edición, la imagen es aún más clara, porque se trata de un dibujo que presenta en la parte superior una figura horizontal y en la inferior, una vertical, lo que podemos relacionar con la imagen de la muerte y la regeneración: Cortejo y Epinicio. La segunda lectura sobre el título se refiere a considerar el poema como un pórtico (el autor dirá un "preludio») y el poema final como un cierre, que es más bien un retorno («De la tierra y el hombre» se llama en la primera edición; «Pasión» en la más reciente). El «Preludio» es uno de los pocos textos, por no decir el único, que se traspasa

\footnotetext{
Nos referimos aquí a las primera edición de 1949 y a la última del año 2002. La segunda, al parecer, no tiene diferencias con la última. Al respecto, Jaime Concha ha señalado que «si <epinicio» representa un género bélico por antonomasia - himno triunfal o canto de victoria- obviamente es lo que el libro de Rosenmann excluye deliberada y sistemáticamente [...] ‘Cortejo〉 en cambio, si bien por contigüidad al otro término pudiera adquirir el matiz de desfile militar o algo así, tiene también la connotación habitual de acompañamiento funeral que resulta más cercano al clima dominante de la serie de poemas». Concha se refiere también a la posibilidad de relacionar el título y el texto, indicando que lo barroco y heráldico de la portada transmiten signos de otra época y una serialidad distinta, aunque tiene una lejana conexión con el lenguaje que evoca el título (4).
} 
casi sin variación de una edición a otra. La variación es mínima: el hemistiquio «el nimbo pasaremos» se transforma en "aureola sin imperio», pero el núcleo central predomina. El preludio ejerce el sentido de una entrada en un tiempo-lugar que se sitúa en un después, un universo desplazado que se muestra a través de imágenes desorbitadas que evocan la muerte: «después el viento entre dos cimas [...] y las mareas rojas sobre el día [...] el buitre morirá [...] después el viento». A partir de esa extensión en el espacio, que es extensión en el tiempo, el poeta intenta sumergirnos en un mundo siempre desplazado en el «después», el «nunca», el «vacío» y el «entre». Conceptos que aluden a la unión con una trascendencia que se desarrolla entre el movimiento y la inmovilidad: «el viento entre dos cimas». La partitura de los poemas aparece «entre» el origen y el final, entre el preludio y la pasión. De la muerte-noche surge una muerte-luz: «Extendido en lo nunca un solo cuerpo callado como luz». Es hacia ese lugar del «nunca», del «después», que tiende todo el despliegue que ejerce la memoria en el poemario con sus desplazamientos hacia un pasado que sólo relumbra en los sueños del inconsciente, como un «entre» la vida y la muerte, pero también como un "entre» después de la muerte.

En el otro extremo se completa el círculo con el texto 67 del libro original que se titula, como ya dijimos, «De la tierra y el hombre», en donde la tierra parece revitalizarse con los huesos de los muertos: "Agua de tierra y sal de tierra penetran los huesos». Cuando "los cuerpos caen en la tierra», "crece la luz», "la risa y el llanto saben de lo hondo» y la «cubierta del odio está plena de tierra». Todo se hace tierra, la cual hace germinar de nuevo la vida y a su vez se alimenta de los cuerpos que caen y se representa en el canto del hombre, que es su «canto de tierra». No sólo los cuerpos caen y mueren, sino que todo muere en la tierra y a la vez brota de ella: «Todo muere./ Mueren la rama del aire y el aire./ Mueren ala y pájaro, brote y pétalo,/ Mueren el brazo del hombre y el hombre» (I: 154). La tierra adquiere un carácter antropomórfico y se transforma en un bálsamo para el hombre a través del llanto: «El hombre penetra a la tierra./ Y el llanto de la tierra humedece la frente del hombre»(I: 155). La tierra se transforma en cascada, «lecho de luz», en madre que hace dormir, en cuna que «prepara el sueño» y que nos hace navegar «a la paz». Pareciera que en el poema final, "cortejo y epinicio» fueran lo mismo, en una síntesis donde el «dormido» que junta huesos y sueños se hace uno con la tierra transformadora: «y el dormido no sabe/ si lo que su sueño roza/ es la tierra o sus huesos» (I: 156). Aunque en el poema "Pasión» de la segunda versión se mantienen los elementos centrales del último poema de la primera, cambia el lugar del sujeto, que de impersonal pasa a representar al muerto en primera persona: "Agua de tierra y sal de tierra me penetran. Desvelo mis raíces/ con mi canto de tierra alborozada [...] Velada epifanía hacia los cielos, mueren mis brazos. Muero». Una «dialéctica negativa» que surge en varios textos y que alimenta también éste: tierra y llanto se precipitan en el abismo, pero luego «la tierra se endereza», adquiere alas y vuela ahora a través del canto: "Crea la tierra/ alas: crea tierra». La tierra es luz que se precipita en todas las direcciones o mejor dicho, fuera de toda dirección: "y es la tierra de tierra/ y es el éter de tierra». El sujeto que se presentiza, se hace ahora tierra, raíz, germinación: «Desvelo mis raíces/ con mi canto de tierra alborozada [...] cruje la tierra toda/ su semental de tierra» (I: 153). Como en el texto de la primera versión, "hay que dormir el sueño de la tierra» y "no ha de cesar el tiempo su pasión", pero el final queda abierto al no saber "si hueso o tierra [es] lo que roza el sueño». Es decir, al igual en el texto 1, el dormido no sabe si terminará en el silencio o en un retorno a la pasión del «Quiero». Vida y muerte, aparecer y desaparecer, amanecer y 
noche, aire y tierra se funden y disgregan en una unión-desunión permanente que reaparece en el sueño. La pasión germinadora que une la muerte con la vida reaparece luego en el breve poema XIII de la primera versión (XVII en la segunda): «Acabo de morir: soy un recién nacido".

En todo el libro que citamos, predomina el tópico de esta muerte lenta que impregna la conciencia del sujeto y que se amplía a todos los seres vivos, así como a la naturaleza: «nos vamos tornando sombra/ sombra y sueño en la sombra» (V-31). Sin embargo, por los intersticios de ese escenario que el discurso poético llena de una atmósfera densa y sugerente, plagada de amenazas, asoman en el sujeto (o los sujetos de los poemas) recuerdos y emociones que convierten la memoria en el único sostén de toda existencia. Esa «habla desde la muerte» que arrastra las cosas a su destino desde el origen es uno de los modos que tiene esta poesía de instalar "otras voces [que] hablan a otras voces». Es la conciencia de que el territorio de la vida es una carrera acelerada que para «lentificarse» tiene sólo algunas precarias posibilidades.

En varios de los otros poemas del libro, se ratifican los elementos anteriormente señalados, aunque ahora se mezclan con otras formas de exorcizar la muerte, especialmente al instalar en los textos el jardín de la niñez (una naturaleza humanizada) como espacio que se imbrica con los juegos infantiles, pero también con un ambiguo erotismo que impregna los objetos y con la asunción del dolor y el sufrimiento ínsito en lo humano, morigerado por un discurso irónico y sarcástico. En el poema «Diálogo sepulcral» (XI en la primera edición y XIII en la segunda), se lee: «Hace ya mucho tiempo que me come la tierra / y por eso comprendo la negra empuñadura» (I: 42). Esa «negra empuñadura» refiere a la muerte, lo que se aclara en la segunda versión, donde se lee: "icarcelero! Ya mucho que acongojas [...] Empújame a tu apremio» (II: 41). El sujeto apostrofa a la muerte, usando la antítesis como forma de integrar a ese carcelero de la vida para poder resistirlo: «Tráelo a tu memoria, húndelo en tus mejillas,/ ábrelo todo y sángralo/ que recordando, olvidas» (II: 42). El poema termina expresando la idea de la vida como agonía: «Dentro de ti esta vez un hombre agonizaba», verso que en la segunda versión se hace más rotundo y terminante: «Dentro de ti, por fin, agonicé». El jardín de la infancia vuelve a aparecer en el poema «Inmortales» (XIV en primera versión y XVI sin título en la segunda), situado al final de la sección SPHERA, como un elemento que trata de detener la atmósfera mortuoria que rodea al ser humano. Se inicia diciendo: «Basta mirar las rosas de vuelta a los rosales, / basta lamer la brisa,/ basta cantar la luz y herir los nidos/ la luna muere hoy, pero nace mañana». Ese eterno retorno del jardín y de la luna contrasta con «la noche de hoy (que) es una antigua noche que [...] encuentra su regazo en las [...] mantas del luto que hoy es dueño del sueño de los hombres» (I: 47). Así es como las hojas se secan, pero (ahora) están en primavera y así es también como "un niño es un anciano que mañana será/ a escondidas de Dios, una criatura de pan de sortilegio» (I: 47). Esa permanente dialéctica entre el trabajo de la muerte y las formas (poéticas) de eludirla o lentificarla, aparecen una y otra vez en los poemas. En «Dafne árbol» es de nuevo el deseo del sujeto de integrarse a la naturaleza, ahora con placentero autoerotismo: «Me entrego a placeres morados/ y dúrame el ansia./ Muchachos: saladme en la hierba,/ exprimo pinares, pinares./ Aquí estoy aullando caricias. Me apoyo en el sol de mis ramas. Mi anhelo recorre los álamos» (I: 110).

En «Cosecha de sosiego» (V en la primera versión), también se representa la «lentificación» de la muerte, a través de la contraposición entre «cosecha» (producción humana, 
germinación de vida) y el "sosiego", que alude a la tranquilidad pero también a la quietud, en este caso en relación a la muerte: «Y echamos tierra encima/ y olvidamos los ojos/ cerrados y la boca/ quebrada. Bajo el polvo/ los párpados sin fragua,/ los ojos» (I: 30). Tierra y polvo aparecen otra vez en su doble función de cubrir a los muertos y al mismo tiempo cuidarlos en su sueño y hacerlos germinar. El «nosotros» describe la manera en que nos vamos separando del muerto, que como diría Vallejo siguió muriendo, pero luego entendemos en el transcurso del poema que ese muerto somos también nosotros mismos. La fusión se produce cuando el sujeto plural en primera persona señala que «olvidamos la frente y las arrugas, las manos y las uñas» (I:30), para luego incorporarse al proceso de desintegración: «nos vamos sumando a la noche a la hora dorada de las siembras» (I:30). Así, la regeneración de la vida natural (siembra, surco, bosque, aromos en flor, gavillas, árbol) y el acompañamiento de Dios o ambos integrados («levantamos las manos/ para que Dios les hable»; en la segunda versión; "Dios madura en el polvo», 32) sirven de contraste, pero también de comunión a la mortal vida humana, que se sumerge en el sosiego (el sueño) de la muerte: "Y nos vamos tornando/ sombra y sueño en la sombra» (I:30). En el poema IV, el tópico de la muerte en vida se muestra a través de la idea de destierro y devaluación de la vida en un sujeto que está a la intemperie: «Con su cuerda invisible me ahorca/ la baldía intemperie; los duendes/ zarandéanme a gajos agónicos./ ¿Qué destierro! ¡Qué escombros!» (I:29). Ese sujeto «desterritorializado» se mueve en un presente de caída y degradación que anhela trascender para superar su vida mecánica y su conciencia de alienación: «Me refugio en los silos más hoscos / de la áurea desgracia [...] Estropajo que tengo de emblema se me enrosca en el cuello: es huirme, es no hallarme, es verterme sin ruido... jes morirme!» (I:29). La posibilidad de trascendencia parece darse a través de la imagen de la gota de agua cayendo y produciendo un sonido (música) y un sentido (germinación de la vida en la tierra) distinto. El instante de la gota de agua que cae es una extensión del presente que aminora «la baldía intemperie» y el «destierro». En la segunda versión, la modificación desde «va a caer y mi sino está tenso» (29) a «va a caer y mi sino se tensa» (31) permite presentizar al sujeto como si estuviera dentro y fuera de la gota de agua (conciencia de su propia posibilidad), a la vez que el verso que se agrega «abrevando la fiebre en cenit», parece aludir a que la gota abreva y abrevia la fiebre alta que se sufre para ser otro. El poema, en su final: «Permíteme oír cómo cae/ esa gota de agua, Dios mío!», similar en ambas versiones, expresa una apelación desesperada del sujeto a la divinidad, que le permita instalar lo esencial (el movimiento de la gota detenida en el espacio) en lo transitorio (el momento en que la gota cae), como conciencia de una posible trascendencia.

\section{PAÍS MÁS ALLÁ: ESPACIO DE LA MEMORIA Y DE LA TRASCENDENCIA}

De País más allá sólo conocemos la edición de 2004, que se compone de un epígrafe que es un texto introductorio de dos versos («Infancia y nada: enlaces que borro, dibujándome»); el «Apresto», una especie de obertura que entrega la atmósfera; el concierto central, compuesto por 39 textos numerados sin título; y el «Adiós», una especie de cantata terminal que cierra el libro. Como en otros poetas coetáneos (Teillier, Barquero, Lihn, Rojas, Alberto Rubio, Delia Domínguez, Pablo Guíñez), el reino de la infancia representa 
también aquí una búsqueda en la memoria y un pre-texto para auscultar el presente y el futuro. Pero sobre todo, se trata de describir la multiplicidad de sensaciones, emociones, visiones y actos que la memoria retrotrae como signo del dibujo de una vida haciéndose y deshaciéndose. Es por ello que el «Apresto", su primer poema, se instala en el extremo de la nada, donde el sujeto desdoblado entre un yo y su sombra es apostrofado, cuestionado, increpado: «¿Qué sientes, di, qué sientes?» (13) y situado en una especie de transmigración hacia el país más allá, ése en donde «infancia» y «nada» se unen indisolublemente.

Y no es que en el poemario no aparezcan las mismas obsesiones de los otros libros: mortalidad, desconsuelo, horror, conciencia inapelable de la muerte, pérdida de una inocencia original. Aquí también afloran los cultismos y manierismos propios de su estilo, los neologismos, las palabras compuestas y las conversiones gramaticales, todo ello conformando un friso de acicaladas exploraciones verbales y pronominales donde lo arcaico resuena siempre como novedoso, y los relumbrones hirsutamente neomodernos se insertan majestuosos en el mar heterogéneo de la frase: ímprobo, socarrón, lauro, medroso, pestillo sinuoso, moño votivo, cerril sifón, meridiano capitel, calígine, íncubos y muladares que flotan entre las personificaciones de los objetos y los fantasmas de los personajes, que se mueven alrededor de ellos como si la existencia fuera más bien el preludio de la esencia de las cosas. La singularidad de la experiencia se despliega en un juego de visiones, donde la pirotecnia no ahoga jamás la imagen central de lo que se quiere decir, contar, expresar, como en ese dechado de síntesis que es el texto 26: «Vendimia: el aro. El pabellón reposa» (117). O en esa imagen relampagueante de la muerte, que aparece en el 33: «La eternidad apura. Presos,/ acreedores,/ unos huesos/ aterrados/ peñascos celadores,/ entibiadnos con fuegos de frescura»» (147).

Pero más allá de sus registros particulares, este libro se centra en la experiencia de la infancia, jardín secreto de donde surge un cúmulo de otras experiencias que se enlazan con el origen y el final, el nacimiento y la muerte, la infancia y la nada. Entretanto, se busca la sobrevivencia, por medio del dibujo que hace el individuo de su propia vida, de su entorno, de los seres queridos (Ester, Lajda, padre, madre), de su sueño, su paisaje y su muerte, esa «novela matutina» que el tiempo hace y deshace y que un día «cuando el árbol me alargue su raigambre [...] ceñirá enredadera» (125), es decir, tendrá una continuidad o una trascendencia, porque aquí hay una visión trascendental del ser humano, ya sea a través de lo que dice el poema, de la música, de la paráfrasis de la divinidad, de la presencia del otro o del vuelo bruñido del aliento. De ese modo, «el país más allá» es un hueco que se llena de silencios, de memorias, de preguntas que no requieren respuestas, de imágenes obsesivas que se agolpan en el recuerdo (panteones, misas, sudarios, rastrojos, esqueletos, zócalos, medallones) y buscan quebrar la nostalgia de ese tiempo imposible, que se instala como una espacialización de la conciencia. El ambiguo sujeto (a veces un yo que describe o recuerda, a veces un apóstrofe del tú, a veces una voz que se pierde en el océano verde de la naturaleza), bucea entre los hilillos de una tenue corriente de conciencia, que se licua en fulgores cromáticos o reverbera en una batería de sonidos, trazando la búsqueda fantasmagórica de un tiempo anclado en la memoria en donde ocurren cosas imponderables, las cuales son percibidas más por los sentidos que por la reflexión. El o los sujetos se pierden en la limpidez de un mundo-naturaleza sin jerarquías, dentro del cual recobran un sitial de inocencia que quizás nunca tuvieron, pero que la corriente de la memoria recaptura con un discurso que le devuelve su origen prístino. Si bien la particularidad de las experiencias resignificadas no siempre parece 
encajar en la totalidad discursiva de los textos, resulta evidente que el «país más allá» es la tabla de salvación de ese dibujo que traza una línea carnal y natural entre el aluvión de objetos, sucesos e imágenes de esa madrugada semifeliz (con sus sugerencias cromáticas y eróticas) y el umbral de este adiós, también "país más allá», pero ahora con toda la carga que conlleva ese «viento que cruje», esa «fragua que cruje», puerta que conduce al encuentro con los seres amados (padre, madre, hermanas) en una trascendencia que se llena de mundo más allá de la muerte. Así es como el inicio del poema I, «madrugadas, goznes, azar contra azar», (17) se entronca con el poema final: "goznes, fragua, goznes: azar el azar» (177), para cerrar un lugar y abrir el otro, ambos puntos de encuentro, uno en la memoria, el otro en la muerte, como posibilidades únicas de anudar lo que en la vida está desanudado.

En definitiva, el poema se realiza como lugar de encuentro, un gozne escritura que da cuenta de una realidad contradictoria y busca, en la experiencia del lector, cruzar juntos el umbral del «país más allá» para preguntar y preguntar a través del espejo: "¿Por qué tus trenzas, hermana,/ semejan trenzas de la tierra?» (XXXV: 157), o bien, "mamá ¿me besarás si me voy a acostar? [...]/ y entrégame tu beso aunque sea de lejos; / entrégame tus brazos aunque sea de lejos;/ calígine, dichoso,/ estrecho tu ternura,/ y no llores, no llores, estoy bien abrigado» (XIII: 65-66). Trascendencia espuria a la que se vuelve una y ora vez con esperanza, con emoción, con anhelo y en cuya proyección se arraiga el poema, buceando en el espacio-tiempo memorioso el reencuentro con un sí mismo que acerca al otro y al mundo, manteniendo a distancia el angustioso sueño de la muerte.

\section{OTROS TEXTOS: EL RETORNO A LA FUENTE COMO TRASCENDENCIA}

En El mensajero. Cortejo y epinicio II del 2003, el lenguaje visionario del autor mantiene el sentido musical de los poemarios anteriores, pero el discurso se va haciendo cada vez más austero y concentrado, buscando significados más justos y exactos en cada verso o enunciado. Un trabajo arqueológico en constante depuración, que incluye la incorporación de formas lingüísticas arcaicas, actuales y reinventadas, lo que permite el dinamismo sintáctico y semántico, desde una fruición estética en que humor, ritmo y oralidad producen efectos plásticos y musicales de inusitado esplendor. Junto a ello hay que considerar la rigurosa estructura melódica y religiosa que tiene el texto, ratificada por la visión que tiene el propio autor sobre su producción.

En ese texto-libro afloran de nuevo una serie de preguntas que ya se plantearon a propósito de Cortejo y epinicio I. ¿Quién es el mensajero?, ¿cuál es el mensaje?, ¿hay una salida ahora al cortejo de la muerte a través del mensajero del epinicio?, ¿estamos en el umbral-mensajero que trae la fuerza del origen? A través de esa resumida constancia no podemos dar cuenta de las dificultades que presentan éste y los otros libros, sino sólo tocar tangencialmente el tema que nos ocupa. Desde el anuncio de la primera parte, «VITAMORTIS», hasta el «QUID» final, tenemos como recurrencia la búsqueda de una trascendencia que se sabe utópica, pero aun así se busca y conjura a través de un discurso exorcizante, reiterado, de una complejidad oscura y sin embargo con destellos luminosos.

Los textos abundan en alusiones a la transitoriedad de la vida, la amalgama con la muerte cuyo cortejo ahora se corteja para auscultar (integrar/ahondar) el otro lugar (la 
tierra, la naturaleza, los rastros de la divinidad, el sentimiento del mundo), en un ritornello obsesionante que es parte de la búsqueda fundamental del poeta. Así en el poema I ya se muestra la «vacante rectitud» (el viaje hacia el vacío y el fin de la vida que implica ética y/o la corporalidad recta: «rectitud») y que conduce a que «transitoria, mi carne/ finará más aún», incluyendo un neologismo que marca el movimiento metonímico del cuerpo hacia su final mortuorio. Esa visión se ratifica en el poema II, «La cita», donde el sujeto anuncia: «Preguntarán en casa/ por mí. ¡Tanto feriado sin tu zarpa!/ Sepelio, ¿no me amas?». Premonición de la muerte y exploración de su movimiento y sus efectos, no como final sino como una relación vital que se esencializa en la vida. En muchas ocasiones, esa relación vida-muerte-vida aparece asociada con los objetos, ya sean naturales o humanizados: el arrope, la alcachofa, las compoteras, el aljibe, las mazorcas, las camisas, los gusanos, etc. La percepción de extrañeza frente a sí mismo, al otro o la otra, a los objetos, se hace cada vez más aguda en el poemario, porque el discurso llega a niveles de esencialidad, de descoyuntamiento, de fragmentación, de intensificación aún mayores que en los libros anteriores. Ejemplifico con algunos fragmentos: «Muy suave, inequívoca,/ almohádame y mádreme y créceme./ Oh, blanca tiniebla de fijeza fija./ ¡Desciéndeme, Nieve!» («Conjuro»); "Cuánto leerme: fusiforme armario: moscardón huroneado en la escudilla:/ prestidigitación con mantequilla:/ pastelería de papel de diario:/ circundante intestino, a barquinazos: jofaina hecha pedazos» («Pásim: diorama»); «Las margaritas se emperejilan:/ unas a otras,/ ¡habrase visto!:/ supremas dueñas del aroma;/ los nimbos, predio,/ y el predio, nimbos [...]/ ¡Nidos, bullidme glaucopajizo!/ ¡Maizales cercos!/ ¡Untos sandiales!» («LV»).

Un ejemplo paradigmático del deseo de muerte se encuentra en el poema «LXIII», escrito excepcionalmente en alejandrinos con 12 estrofas, de las cuales hay ocho de tres versos cada una y tres de cuatro versos, todas con estructura paralelística y construcción anafórica, lo que permite intensificar el sentido musical y conjurativo del texto. Basado en el refrán que encabeza el primer verso ("Cómo me gustaría ser esa oscura ciénaga»), su reiteración y las variaciones de ese deseo, expuestos en forma de ensalmo o encantamiento, dan cuenta de la contradicción de un sujeto que sufre la vida, que apela a una divinidad en la que se quisiera creer "para no ser» y, lo que es más terrible aún, al que se quiere olvidar antes de ser: "Cómo me gustaría olvidarte, Dios mío,/ Cavílame en tu nada. ¡No me hagas volver nunca!». Poema en que la búsqueda se subvierte en un deseo de borrar la memoria y con ello borrar cualquier posibilidad de utopía o trascendencia humana. Deseo que se manifiesta en aspiración a «jamás haber nacido», «lograr morirme ahora», "rodar por el vacío», "ser el cero del polvo», "no me hagas volver nunca», etc., es decir, no tener historia. Pero también deseo imposible, ya que el propio deseo del sujeto se inscribe en la historia y en el poema como búsqueda de una trascendencia de la impotencia. El poema final del libro y único de la sección QUID («CIII») resume tal vez el intento: «Por resultado, versos:/ paráfrasis de Dios». El poema emula a Dios en ese afán de dar cuenta del deseo humano de trascendencia, que le permite nombrar el mundo y humanizarlo, pero que también muestra sus límites.

En El Cielo en la Fuentel La Mañana Eterna de 2004 se reitera ese deseo del sujeto de volver a la fuente (la mañana eterna), origen, juventud, donde el cielo y la fuente se unen como en un espejo donde se visualiza el vértigo del tiempo. Sin embargo, la imagen que perdura a través del libro es la del corazón como centro de las vivencias que unen lo corporal con la conciencia y que representa la vitalidad del ser humano. El cielo y la 
fuente se reflejan el uno en el otro creando el sueño de un deseo de infinitud juvenil, que vuelve una y otra vez a la infancia persiguiendo el Narciso que se busca inquietamente a sí mismo, en un gesto que intenta unir belleza y conocimiento. En este libro, el viaje de Jesusa (personaje central del poemario), es un retorno conceptual a las fuentes para cumplir su recorrido desde la sombra a la sombra, donde la negación se hace latido y sangre, afirmación del corazón viajero que se continúa de una existencia en otra: «Mi corazón —dijo-, mi corazón/ no está [...] Yo tengo mi morada/ aquí./ Repetiré la sombra?/ ¿Me ceñiré, venciéndome?» («El libro del camino, I»). La luminosidad del presente, la sombra que será, la nada que complementa al ser que soy y que no seré, «los ardores [que] ondulan y sucumben» («XVII»), pero siguen su viaje hacia la sombra que también es viaje por el conocimiento, son elementos que dan cuenta de esa búsqueda que ahora se centra en Jesusa: «Jesusa trepó a los hombros de Jesusa,/ afanó su dogal con la fragancia de las clavellinas/ y se dirigió a las montañas./ Mañana será tarde./ Ayer era temprano./ Hoy no puede ser». Por otra parte, el personaje Pedrito, de la sección «La Mañana Eterna», afirma una verdad que se entroniza con la imagen de la copa: el personaje masculino activa el amor y el erotismo como el deseo de la plenitud de la vida y como conocimiento de una juventud que busca eternizarse en la conciencia: «la frente de Pedrito [...] ¿Renuevo/ de malezales?/ —Riégame-/Joven, la piedra./ Hierba, la altura./ Cráneos,/ los vértigos». («VI»). De la piedra a la hierba, riego que renueva y devuelve al sujeto al vértigo de la vida y que se une al viaje de Jesusa a través del recuerdo del amor, que también es viaje hacia el origen: «¿Mi boca o la tuya?-/ recíbenos, joyel: día sin día: cosquilla de racimo de impaciencia» («VII»).

Por último, un breve comentario sobre Poesiectomía, obra publicada en 2005. En este libro el discurso es cada vez más sintético y breve, cada vez más punzante y filoso. Como ha indicado su autor, son epigramas de la vida privada, preguntas que investigan y que constatan, teniendo como trasfondo una partitura musical, una sustancia rítmica que alude a las relaciones entre el ser y la nada, entre el sujeto que vive y sueña y el vacío. Pero fundamentalmente estamos frente a una vivisección de la propia poesía, a un discurso que se levanta frente a sí mismo como un metalenguaje que introduce ahora no sólo el retorno a las fuentes del ser sino también del lenguaje mismo. Se releva por sobre todo la música: ritmo, armonía, métrica, canto, sonido, anáforas, onomatopeyas, uso de la oralidad, interrogaciones que son afirmaciones que a su vez se convierten en interrogaciones de nuevo: todo contribuye a acercar la voz y la escritura. Los poemas se transforman así en un caleidoscopio de elementos, cosas y seres humanos en constante movimiento, donde la sombra y lo luminoso, la vigilia y el sueño, el texto y la realidad estructuran una matriz de conocimiento de la realidad en que prevalece el «siendo» del poeta empírico, cuya búsqueda incierta y a veces casi vacía culmina y vuelve a empezar en el último poema, como el sentido transitorio del sinsentido humano: «Me prolongo en el lecho./ Las rapideces, lentas./ ‘El lápiz〉, ruego a tientas./ Escribo: ¿Escribo〉. Y fecho» (XCII). 


\section{FINAL}

Podríamos continuar hilando en otros textos de Rosenmann-Taub la manera particular que tiene el poeta de buscar una trascendencia, escarbando en los orígenes de una memoria que se universaliza desde lo personal y que da sentido al presente para exorcizar un futuro siempre amenazado por un sentimiento de pérdida y orfandad. De un modo cada vez más afilado y tenue, los poemas se cierran sobre sí mismos: "¿Y para qué acudimos?/ Para irnos», señala el sujeto del texto LI de Auge. Y en el LVII del mismo libro: "No había mar: no había ni su huella:/ no había ni el vacío de ese día postrero./ Miré el mirar del navegar que espero". Instalado en ese momento culminante del mirar, el sujeto percibe los recuerdos desde el naufragio (la muerte): conciencia desdoblada que crea una epifanía desde la experiencia y la memoria de un tiempo imaginado e imposible. Es así como los sujetos de estos poemas intentan llenar permanentemente el sentimiento de precariedad de la vida, con un origen que se escabulle, se vacía o se torna infructuoso. Señalemos, para resumir, que por los intersticios de esos discursos, asoma una atmósfera densa y sugerente, que a pesar de las amenazas instalan recuerdos y emociones que convierten la memoria en el único sostén de la existencia. Ese «hablar desde la muerte» que arrastra las cosas desde el origen es uno de los modos primordiales que tiene su poesía de instalar "otras voces [que] hablan a otras voces». Es la conciencia de que el territorio de la vida es una carrera acelerada que para «lentificarse» tiene sólo algunas precarias posibilidades.

David Rosenmann-Taub ha dicho que «el presente es el lugar donde me instalo a escribir en dirección al pasado y al futuro", y agrega: "¿Cuál es la razón de crecer? ¿Cuál es la razón de recordar? La conciencia del despertar cuando ya no estando aquí, nos dirigimos hacia la niñez del allá» (Lennon).

Conminación del poeta para cruzar juntos el umbral del país más allá, para preguntarnos qué sentimos y ver si «confundidos con el mediodía/ y la brisa nos cambia el rostro» (País Más Allá, 173).

\section{REFERENCIAS}

Alonso, María Nieves. «Tierra y alma, en la luz, se precipitan». Prólogo a Cortejo y Epinicio. Santiago: Lom Ediciones, 2002. 5-15. Medio impreso.

Arteche, Miguel. "Los Surcos Inundados. David Rosenmann-Taub». Diario El Mercurio, 29 de mayo de 1953: C 3. Medio impreso.

Berger, Beatriz. «Todo poema en mí, tiene su partitura». Entrevista a David RosenmannTaub. Diario El Mercurio, Suplemento Revista de Libros, 6 de julio de 2002: 6-7. Medio impreso.

Castellanos, Laura. «Vine al mundo a aprender». Entrevista a David Rosenmann-Taub. Diario Reforma, 14 de mayo 2005: 1-3. Medio impreso.

Concha, Jaime. «Nace una singularidad: el primer libro de David Rosenmann-Taub». Revista Iberoamericana 224 (julio-septiembre 2008). 1-18. Medio impreso.

Correa, Carlos René. «Los Surcos Inundados. David Rosenmann-Taub». El Diario Ilustrado, 29 de mayo de 1952: 2. Medio impreso. 
Cussen, Felipe. «Juegos metafísicos en la poesía de David y Mauricio Rosenmann-Taub». Anales de Literatura Chilena 14 (diciembre de 2010). 173-191. Medio impreso.

De Miomandre, Francis. «La poesía de David Rosenmann-Taub en Cortejo y Epinicio y en Los Surcos Inundados». Hommes et Mondes (1951). 6. Medio impreso.

Del Solar, Hernán. «Cortejo y Epinicio. David Rosenmann-Taub». Diario El Mercurio, 10 de junio de 1979: 3. Medio impreso.

Díaz Arrieta, Hernán (Alone). «Cortejo y Epinicio. David Rosenmann- Taub». Diario El Mercurio, 22 de enero de 1950: 3. Medio impreso.

Fasola, Franco. «Entrevista a David Rosenmann-Taub». Semanario La Nación Domingo, 22 de agosto de 2004: 1-4. Medio impreso.

Gandolfo, Pedro. «David Rosenmann-Taub: un enigma poético». Diario El Mercurio, Suplemento Revista de Libros, 27 de mayo de 2007: 1. Medio impreso.

Lennon, Maureen. «Rosenmann-Taub, el mito viviente de la poesía chilena». Entrevista a David Rosenmann-Taub. Diario El Mercurio, 6 de diciembre de 2004: C 13. Medio impreso.

Miranda Paula. "Quince autocomentarios de David Rosenmann-Taub: fin al hermetismo». Revista Chilena de Literatura 74 (abril de 2009). 267-270. Medio impreso.

Ortiz, Lautaro. "Apartado de todo, lejos del mundo». Entrevista a David RosenmannTaub. Poesía.com (junio de 2002). 1-6. Disponible en Biblioteca Virtual Miguel de Cervantes. Sitio Web. Fecha de ingreso: 16 de diciembre de 2011.

Rodríguez, Ignacio. "La brevedad de lo absoluto: Los Despojos del Sol». Diario El Mercurio, Suplemento Revista de Libros, 5 de mayo de 2006: 1-2. Medio impreso.

Rosenmann-Taub, David. Al rey su Trono. Buenos Aires: 1983. Medio impreso. - Auge. Santiago: Lom Ediciones, 2007. Medio impreso. . Cortejo y Epinicio. Santiago: Cruz del Sur, 1949. Medio impreso. . Cortejo y Epinicio. Buenos Aires: Esteoeste, 1978. Medio impreso. . Cortejo y Epinicio. Santiago: Lom Ediciones, 2002. Medio impreso. . Cuaderno de Poesía. Santiago: Taller Edición 99, 1962. Medio impreso. . El adolescente. Santiago: Caballo de Fuego de la Poesía, 1941. Medio impreso. . El Cielo en la Fuentel La Mañana Eterna. Santiago: Lom Ediciones, 2004. Medio impreso.

. El Mensajero. Cortejo y Epinicio II. Santiago: Lom Ediciones, 2003. Medio impreso.

. La enredadera del júbilo. Santiago: Revista Atenea y Cruz del Sur. 1952. Medio impreso.

. La opción. Cortejo y Epinicio III. Santiago: Lom Ediciones, 2011. Medio impreso. . Los Despojos del Sol. Buenos Aires: Ananda Primera, 1976. Medio impreso.

. Los Despojos del Sol. Santiago: Lom Ediciones, 2006. Medio impreso.

-_- Los surcos inundados. Santiago: Cruz del Sur, 1951. Medio impreso.

-_- País Más Allá. Santiago: Lom Ediciones, 2004. Medio impreso. - Poesiectomía. Santiago: Lom Ediciones, 2005. Medio impreso. - Quince Autocomentarios. Santiago: Lom Ediciones, 2008. Medio impreso.

Rubio, Alberto. «Los Despojos del Sol. David Rosenmann-Taub». Diario Las Últimas Noticias, 31 de julio de 1977: 3. Medio impreso.

Salvador, Álvaro y Erika Martínez (editores). Me incitó el espejo. Antología de David Rosenmann-Taub. Barcelona: DVD Ediciones, 2010. Medio impreso. 
Solari, Cristóbal. «Entre la tierra y el cielo». Diario El Mercurio, 14 de diciembre de 2002: 3. Medio impreso.

Tapia, Patricio. "Contra la improvisación». Entrevista a David Rosenmann-Taub. Diario El Mercurio, Suplemento Artes y Letras, 20 de noviembre de 2005: E4-5. Medio impreso.

Uribe Arce, Armando. «Presentación de David Rosenmann-Taub». Poesía chilena (19601965). Santiago: Ediciones Trilce, 1966. 88-104. Medio impreso.

. «El Mayor Poeta». Diario El Mercurio, 27 de septiembre de 1998: 2. Medio impreso.

Recepción: 18 de octubre de 2011

Aceptación: 1 de diciembre de 2011 